\title{
Study on Urbanization Development Strategy along Wuhan to Xianning Intercity Rail
}

\author{
Senwen Shi and Junqing Zhou \\ School of Architecture and Urban Planning, Huazhong University of Science and Technology, Wuhan 430074, China
}

\begin{abstract}
As the development of "two-oriented society" in Wuhan urban agglomeration, the intercity railway will be an important way of driving the development of urbanization in Wuhan urban agglomeration. Intercity railway shortens the time in traffic between surrounding cities of Wuhan and it brings a lot of people, materials and information. It has also brought opportunities and challenges to the areas along intercity railway. The question is how to seize the development opportunities and coordinate the contradiction between development and environmental protection, and taking a new type urbanization. The paper, studying on the areas along Wuhan to Xianning intercity railway, made a summary of the objective law of urbanization and the influence to the along areas by the intercity railway, meanwhile, had experienced from the developed areas which along the intercity railway both in China and abroad. Then the paper proposed the urbanization development strategy from the aspect of land use, industry, population and transportation on the basis of analysis to be economic base and development conditions of the areas.
\end{abstract}

Key words: Intercity railway, urbanization, strategy.

\section{Introduction}

Urbanization is the important sign of a national or region's social development and modernization, it is also the necessary progress and effective means to promote economic growth and the impassable historical period to achieve economic and social coordinated development. Speeding up the urbanization and making the rural surplus labor into non-agricultural industries or cites is the inevitable trend of industrialization and modernization. Urbanization will be the theme of human social development in the 21 st century.

China is a typical dual economy country, which have thousands of rural surplus labor. There are too many things to be accommodated by agricultural and township enterprises, so the rural surplus labor will turn into cities [1]. Joseph E. Stiglitz, the nobel economics prize winner in 2001, pointed out that as the largest developing country, China's urbanization and the United State's high technology development will be the two major subjects of profound impact on

Corresponding author: Senwen Shi, Ph.D. candidate, research fields: regional and urban development. E-mail: knox.ssw@gmail.com. human development in the 21st century. In 2012, China's urbanization rate has reached $52.57 \%$, and is still developing rapidly [2]. In order to protect the ecological environment and optimize the quality of urbanization, the government will promote the new urbanization process. Wuhan urban agglomeration is one of the pilot areas for the implementation of new urbanization. Construction of Wuhan urban agglomeration intercity rail, strengthening ties between Wuhan and the surrounding areas. It also greatly promoted the urbanization development of this area [3]. This paper aims to promote the healthy development of urbanization policy in Wuhan urban agglomeration intercity railway area for some information and help.

\section{Development Opportunities Brought by Inter-City Railway Construction to Regions along the Line}

Located in the South of Hubei province, Wuxian inter-city rail links Wuhan which is known as the "Gateway of nine provinces" to the north with Xianning city which is famous for its ecological environment to the south (Fig. 1). Starting from 
Wuchang city-the traffic hub of Wuhan, the railway passes the East Lake high-tech development zone, Miaoshan economic development zone, Zhifang town in Jiangxia district, and finally enters into Xianning city via Hesheng. The railway is $90.12 \mathrm{~km}$ long at present, and is expected to extend to Changsha in the future. The anticipated passenger flow will reach 81,400 and 150,350 by the year of 2020 and 2030 , respectively. Along the railway, the train will stop at 14 stations, namely, Wuchang, Nanhu, Tangxun Hu, Miaoshan, Puan, Zhifang East, Zhifang South, Wulong Quan East, Tuding Tang East, Shanpo East, Hesheng Qiao East, Xianning North and Xianning South. The average interval between two stops is $7 \mathrm{~km}$, while the maximum is the one between Wuchang and Tangxu $\mathrm{Hu}$ station, which is $17.7 \mathrm{~km}$. The maximum speed of the train can reach $190 \mathrm{~km}$ per hour, and it takes about $28.5 \mathrm{~min}$ to travel the whole journey.

The construction of inter-city railway will usher Wuhan and Xianning into the "Same Town" age. Accompanying with the shortened distance are the flow of people, material and information, which will greatly stimulate the development of regions along the railway, and speed up their urbanization process.

\section{The Problems Existing in the Urbanization of Regions along the Inter-City Railway}

\subsection{The Slow Pace and Low Quality of Urbanization}

Now, the urbanization level of the regions along the Wuxian railway remains at a low level. Hesheng Qiao, a comparatively well-developed town along the railroad line, only has an urbanization rate of $28 \%$, while the urbanization rate of the rest towns are all between $20 \%$ and $25 \%$. This contrast strongly with Wuhan, the urbanization rate of which reaches $63.8 \%$.

The quality of a town's urbanization is mainly manifested in its competitive power and construction level [4]. Compared with surrounding cities, the towns along Wuxian railway are smaller in scale, with backward construction level and incomplete urban functions. Furthermore, due to the weak economic power and insufficient infrastructure construction, facilities like road, water, electricity, and communication are far from meeting the needs of life and industry.

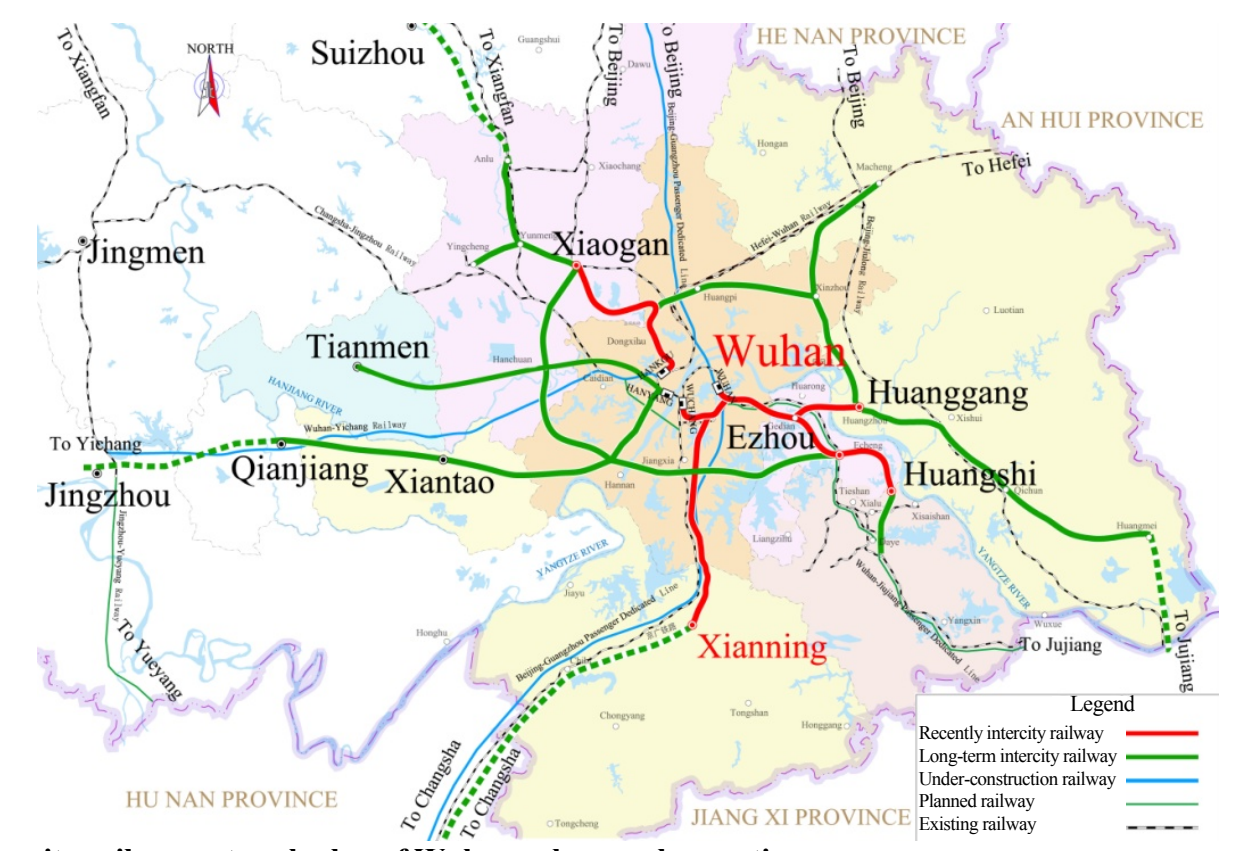

Fig. 1 The inter-city railway network plan of Wuhan urban agglomeration.

Source: The author drew on the base of "the inter-city railway network plan of Wuhan urban agglomeration". 


\subsection{Simple Industrial Structure and Low Motivation for Urbanization}

Since most railway-along towns have long served as transitional areas to big cities, agriculture took the dominance in these places. Though a growing number of other industries have been seen in recent years, the scale of them are all small, which are impossible to exert any significant impact on urbanization process.

The agricultural development in these regions is still backward, with low modernization level and poor infrastructure facilities. The dominant mode of farming in these areas are still crop-planting, and the crop production have low added value.

Agricultural development is the base of town urbanization. The weak agricultural industry leads to the inadequate urbanization power. Meanwhile, as most labors are engaged in agriculture, the transfer of agricultural population to secondary and tertiary industries are restricted, severely limiting the expansion of urban employment in these regions.

\subsection{The Land Resources Loss Caused by Disordered Urban Expansion}

Due to the lack of unified planning and control, the villages and towns along the railway are developing in a relatively disordered manner. With the development of urbanization, the demand for non-agricultural land increases, thus leading to the irrational utilization of land.

Since most of the rural residential areas are constructed freely without an integrated plan, the layout is dispersive, which leads to the phenomenon that one family owns two or even more houses and causes a large waste of land resources.

For the purpose of economic development, a large number of industrial enterprises are introduced into these towns. However, there lacks a unified planning for the distribution of these industires, with most enterprises scattering along the railway. And because of low land rent, all these enterprises tend to occupy an area larger than they need. It is quite common that some enterprises occupy a large area of land only to desert it. It undoubtedly leads to great waste of town land. Since a lot of agricultural land has been turned into industrial land, there is a severe shortage of agricultural land now.

\subsection{The Regional Difference of Urbanization}

Towns along the railroad vary greatly in urbanization level. Wulong Quan town, which is nearest to Wuhan and most affected by Wuhan's economics, developed more rapidly than Tudi Tang town and Shanpo Town. The Hesheng Qiao town, located in the junction of Wuhan and Xianning and boosting beautiful natural environment and good development conditions as well, has also gained a rapid development. Tudi Tang town and Shanpo town, which are located in the middle of the railway, however are developing at a slow pace due to their weak economic foundation and lack of distinctive resource characteristics.

\section{Resources and Transportation Oriented Urbanization Strategy}

\subsection{Analysis on the Motivation Mechanism of Urbanization}

\subsubsection{The Border Bonding Force}

Since the towns along the Wuxian railway are located in border zones of Wuhan, Xianning and Ezhou city, there is a distinct "border effect". At present, there are Jingguang railway which links Beijing and Guangzhou, Huhanrong railway which links Shanghai and Chengdu, Jinggangao expressway, Hurong expressway, 107 national road, and inter-city railways, as well. The inter-city railways will break the limit of administrative boundaries, and the "border effect" will bring about a large number of people flow, logistics, cash flow, technological flow and information flow, which provides good conditions for the conglomeration of production elements [5]. Linking the east to the west 
and connecting the north to the south, this kind of "border bonding force" will become a major driving force behind the urbanization for the towns along the railway.

\subsubsection{Policy Guidance}

In December 2007, Wuhan city zone has been formally approved by the government as the national resource-saving and environment friendly pilot area for social construction. It pushes Wuhan to the forefront of the reform experimented all over the country, and provides great driving force for the development of central areas in Hubei province. With the integrated construction of Wuhan city, policy and financial supports are available for infrastructure construction and environment protection, which is a good opportunity for the urbanization of regions along the railway.

\subsubsection{Driving Force for Economic Growth}

With the opening of inter-city railway, the economy of the line-along areas will surely meet prime time for development [6]. The industrial development will come first. Based on the optimization of agriculture and the development of fine agriculture, we can make full use of the transportation advantage to enable these surrounding cities to undertake the industrial transfer of Wuhan. With beautiful environment and adequate land source, areas along Wuxian railway are well conditioned for the development of high-tech industry. In addition, those areas are closely connected to East Lake high-tech development zone. Relying on the strategic deployment of scientific and research bases and the clusters of new manufacturing industries in the south of Wuhan city zone, we can seize the opportunity and combine with resources to drive a further economic development. The development of economy is the direct driving force for a rapid urbanization.

\subsubsection{Environmental Bearing Capacity}

The main obstacle to the development of Wuhan is the environmental resources, and to be more specifically, is the insufficient supply of urban land. In contrast, there are fewer projects being constructed in cities along Wuxian railway, so the land and environmental bearing capacity there is sufficient. Physical space is central to the urbanization, and only with adequate land supply can we realize the urbanization ultimately. In addition, good ecological environment provides good condition for the development of tourism and the transfer of agricultural population in these regions.

\subsection{The Space Development Strategy of} Urbanization-TOD (Public-Transportation-Oriented) New Town Model

Promoted by Wuxian railway, the regions along the railway are provided with prerequisite conditions to develop the TOD new city (Fig. 2). Since Wuhan's city space is limited by environment, the future development of Wuhan can no longer take on the land expansion mode. To build a public-transportation-oriented TOD new city is an important alternative for the space development of Wuhan city and even the Wuhan city zone. Taking the commuting distance for example, it only takes $20 \mathrm{~min}$ from the railway-along regions to Wuhan downtown. Coupled with the convinient transportation system already in place in Wuhan, inter-city railway can be linked with the intra-city public transportation system to provide people with more convenient means of transportation, bringing the "two city life" closer to reality [7].

The land use of the TOD new city exhibit two characteristics: The first characteristic involves the land close to the hub of public transportation, that is, the CBD (central business district)'s composite function characteristics. Different from most of the downtowns which function as business service center, TOD new city center can incorporate facilities including commercial center, inhabitation, business buildings, schools, hospitals, parks, squares, as well as light industry, making it possible for residents to enjoy these services conveniently in the hub [8]. The concentrated construction of those facilities is also 


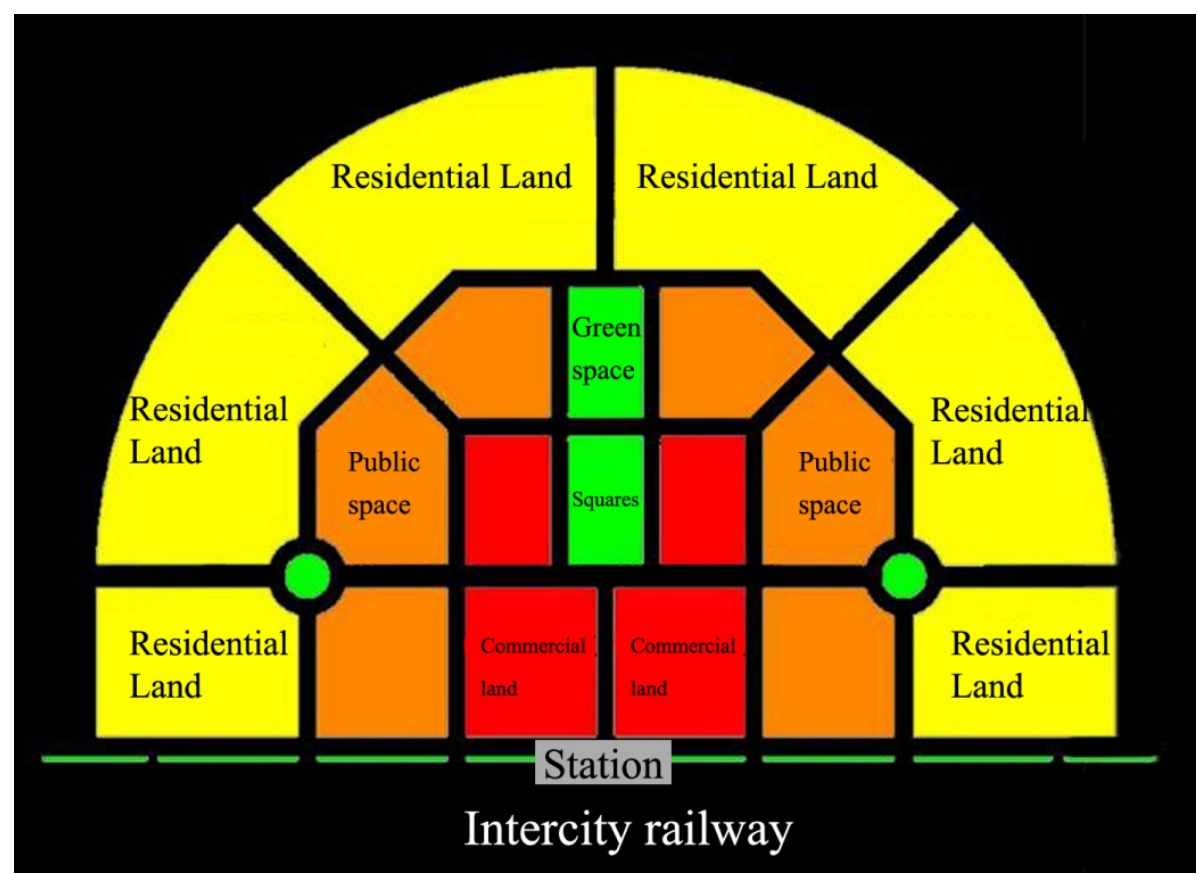

Fig. 2 Land layout mode of TOD new city.

Source: The author drew on the base of "American new urbanism and its theoretical research".

convenient for central water and heat supply, thus reducing the investment in infrastructure construction. The second characteristic is that the building density and dwelling population gradually decrease from the public service district to the surrounding areas, which is compatible with the concentrated deployment of service facilities.

\subsection{Development Strategy for Urbanization} Industry-Based on the Integration of Market, Transportation and Resources

\subsubsection{Characteristic Agriculture and Agricultural} Industrialization

The rich water and mountain resources in the areas along Wuxian railway lead to a weak ecological system. It is important to take advantage of agriculture's function in stabilizing ecological system, to actively construct "agricultural production base" with local characteristics, to promote new agriculture including ecological and tourism agriculture, and to focus on the construction of five pillar industries, namely, aquatic production, vegetables, fruit tea, flowers and plants. In this way, on one hand, the development of characteristic industries of those regions could be guaranteed, and on the other, the ecological environment could also be protected by scientific management. We can utilize limited land resources to develop agriculture with characteristics, promote intensified farming and generate maximum benefit with least cost [9]:

- goal of primary industry development: characteristic development, scientific development, ecological development and scale development;

- characteristic development: strive to develop agricultural industries featured with local characteristics and high economic value, such as characteristic cultivation, high quality grain, vegetables, flowers and plants;

- scientific development: with the geographic advantage of neighboring the agricultural science and technology center of Hubei province, develop scientific and technological agriculture, enhance the experiment and promotion of new agricultural production methods and products;

- ecological development: explore the ways and methods of ecological production; 
- scale development: carry out intensive farming, to try the scale, mechanism, farm village, and to implement the direct and chain supply with supermarkets and catering industry.

4.3.2 The Transition from Traditional Industry to New Industry

The precondition of those towns urbanization is that it is necessary to choose the new industrial form, to replace the traditional mining and processing industries with the modern manufactory industry for the rapid development of industrial economy. The industries as represented by light manufacturing industry and bio-medicine are going to be the core of industrial development.

Goal of secondary industry development: to link industries, to enhance traditional industry, to proceed autonomous development, to create new industries actively, to be the supporting industry and scale industry base of Chunkou automobile industry and Wuhan scientific and technological city.

To enhance the traditional industry: to take the local advantages, to promote the traditional industry's market competitive force with information, high technology, and scale enterprises, to strengthen the traditional industry and to consolidate the regional advantages.

Autonomous development: to encourage self-employment, to support private economy, to play the middle and small sized enterprises' self-growth force.

Characteristic town plus zone economy: to introduce the industry into the zone, to develop the industrial organization form of the industrial zone, and to build characteristic towns along the railway.

4.3.3 To Promote the Modern Service Industry

To develop modern service industry focusing on the three industries: education, modern logistics and tourism.

As the transferring of branch campuses and research centers increase, the regions along the railway could be the first choice of those organizations. With convenient transportation system, the logistic industrial zone as base, the development of modern logistic industry is well conditioned. Some plans are being under the consideration, which are: setting transitional and centralized and decentralized market, to constructing logistic zone, forming delivery and information platform of logistics, implementing mismatched operation strategy and developing characteristic market [10]. The regions along Wuxian railway have numerous mountains, rivers, lakes, and cultural relics and historic sites, which shows strong cultural deposits. As the major part of rural tourism districts in Wuhan, the development of tourism market relies on Wuhan market, as well as its characters, thus to excavate culture connotation, to highlight the core competitive power, to develop biology-centered tourism base on water, mountains, and countryside resources will be the focus of tourism development strategy:

- goal of retrial industry: tourism, research and education base, modern logistics and financial service;

- tourism: to set the concept of large scaled tourism, market and industry; to develop tourism as the pillar industry of the regions along the Wuxian railway; to realize the big leap of tourism;

- research and education base: to promote all types of vocational education and continuing education, to moderately expand the scale, to enlarge good resources, and to improve education level; to set high-tech industrialization system and science and technological service socialization system with the integration of high technology, basic educational research, experimental development relying on universities and research centers, to develop advanced technology achievement transformation base, self-employment base for high-tech talents, and industrial base of high-tech production for exportation;

- modern logistics: with the modern economy conditions, logistics has been the third profit of enterprises. Since business, commercials, and logistics are major industries at regions along Wuxian railway, thus to develop modern logistic industry with the 
combination of express ways, nation road, inter-city railway and the advanced transportation is reasonable;

- financial service: to develop a secondary financial service center, to form large scale and flexible cash flow, to expand the field and productions of financial service, and to provide effective financial service system for enhancing the regional economic development.

\subsection{The Construction of Biological City and Sustainable Development Strategy}

Although the natural resources are good in regions along Wuxian railway, the damage of the environment from urbanization is distinctive. In addition, over cultivation of the aquatic production has also led to the serious pollution to the lake water. Some large lakes, such as Lu lake, Futou Lake and Liangzi lake have also been polluted in different degrees. Therefore, it is necessary to put the biological concept at an important position in the process of urbanization. The following aspects should be taken with focus.

\subsubsection{The Sustainable Use of Water Resources}

The new city construction should be oriented to develop a resource-saving city, to establish water-saving system, to promote new water-saving technique, to improve the re-sue rate industrial water, to take low water consumption technology as the standard of controlling new industrial projects, to carry out water-saving agriculture and to develop water-saving irrigation project; to divide the pollution sensibility of water body, to carry out different biological administrative strategy, to set cleaning industrial system, to provide strict control to the industrial polluted water, and to set a perfect multistage sewage treatment system.

\subsubsection{The Protection of Wetland Resources}

Since there are many lakes and waterways, regions along Wuxian railway have rich wetland resources. However, with the increasing of water pollution and expansion of town construction, the wetland is decreasing, and its pollution is increasing. Therefore, it is necessary to enhance the protection of wetland in the process of new city construction in following ways: to control the ways, types, range, and number of pollution discharge and to create survival conditions for water plants. In addition, a wetland park could be set as a characteristic industry to carry out research about natural biological tourism and wetland, and to drive the regional economic development as well.

\subsubsection{Sustainable Use of Energy and Resources}

An important standard of constructing a biological city is "low carbon". The traditional energy structure has led to serious air pollution, thus the regulation of the structure should be taken in the process of construction, additional energy except oil and coal should be added, to maintain the stability of energy supply based on multi-energy structure. The new industry with low energy consumption should be encouraged to reduce resources consumption and environment pollution. It is necessary to optimizing the urban road system in the process of city planning, to advocate walking and public transportation, to reduce air pollution from motor vehicle's gas and to advocate green travel.

\section{Conclusions}

The intercity railway of Wuhan urban agglomeration will have great impact of the areas which along the intercity rail. But the most important is how to seize this opportunity to get the cross-border development. Base on the analysis of the problem of urbanization development, the paper, combined with the dynamic factors of urbanization development, proposed to combine their resources proposed sites rely on intercity rail development model TOD model.

Meanwhile, they should take the dislocation development in the functional orientation, compared with Wuhan and other major cities, and take different development path. Eventually, a new urbanization development path will be propose, which is the integration of resources, transportation and markets. 


\section{References}

[1] L. Amir, Accounting for Human Capital When Labor Mobility Is Restricted, London Business School Accounting Subject Area, Sep. 2001, pp. 155-161.

[2] K.W. Chan, Urbanization and Rural-Urban Migration in China since 1982, Modern China, July 1994, pp. 243-281.

[3] G.C. Lin, Changing theoretical perspectives on urbanization in Asian and developing countries, Third Word Planning Review 16 (1) (1994) 1-23.

[4] N. Zhu, X.B. Luo, Non-farm activity and rural income inequality: A case study of two province in China, Working Paper, World Bank Policy Research, Dec. 2005.

[5] J. Ma, Study on the construction necessity of intercity rail transit of Wuhan urban agglomeration, Journal of Transportation Engineering and Information 3 (6) (2008) 6-10.
[6] X.B. Li, Analysis of the impact of Wuhan city circle intercity railway on the economic and social, Journal of Technology and Market 19 (5) (2012) 294-296

[7] J. Li, Analysis of intercity rail transit construction of Wuhan urban agglomeration, Journal of Railway Transport and Econmy 31 (6) (2009) 62-64.

[8] X.R. Li, Study on the land development strategy for inter-city rail transport hub, Journal of Urban and Regional Planning 7 (3) (2011) 177-188.

[9] M.S. Bronzini, J.H. Herendeen, J.H. Miller, N.K. Womer, A transportation-sensitive model of a regional economy, Journal of Transportation Research 8 (1) (1975) 45-62.

[10] Q.Q. Jiang, T.K. Liu, H. Chen, A study on the interaction between spatial planning and industry developemen: The case of new industrial districts of Zhuzhou, Journal of Urban Planning Forum 5 (7) (2012) 211-215. 